\title{
Primary surgery versus no surgery in synchronous metastatic breast cancer: patient-reported quality-of-life outcomes of the prospective randomized multicenter ABCSG-28 Posytive Trial
}

V. Bjelic-Radisic ${ }^{1,2^{*}}$ D, F. Fitzal ${ }^{3}$, M. Knauer ${ }^{4}$, G. Steger ${ }^{5}$, D. Egle ${ }^{6}$, R. Greil ${ }^{7}$, P. Schrenk ${ }^{8}$, M. Balic ${ }^{9}$, Ch. Singer ${ }^{10}$,

R. Exner ${ }^{3}$, L. Soelkner ${ }^{11}$, Michael Gnant ${ }^{3}$ and on behalf of the ABCSG

\begin{abstract}
Background: The ABCSG-28 trial compared primary surgery followed by systemic therapy versus primary systemic therapy without surgery in patients with de novo stage IV BC. The present report describes QoL results of this trial.

Methods: Ninety patients with primary operable MBC were randomised to surgery of the primary tumor followed by systemic therapy or to primary systemic therapy without surgery. QoL analyses covering the results at baseline, 6,12,18 and 24 months follow up of 79 (88\%) patients, was assessed with the EORTC QLQ-C30 and QLQ-BR23 questionnaires.
\end{abstract}

Results: There were no statistically significant differences in any of the scales of the QLQ-C30 and QLQ-BR23 questionnaires between the two groups over the time. Baseline global health status and physical functioning were predictors for OS (patients with a higher score lived longer ( $p=0.0250, p=0.0225 ; p=0.0355, p=0.0355)$ ). Global health status, social functioning scale, breast symptoms and future perspective were predictors for longer TTPd $(p=0.0244$; $p=0.0140, p=0.020 ; p=0.0438, p=0.0123$ ). Patients in both arms reported significant improvement on the emotional functioning scale. Cognitive functioning decreased over time in both groups. Younger women had clinically relevant better physical and sexual functioning scores ( $p=0.039$ and 0.024).

Conclusion: Primary surgery does not improve nor alter QoL of patients with de novo stage IV BC. Global health status and physical functioning were predictors for OS and could be use as additional marker for prediction of OS and TTd in patients with de novo stage IV BC.

Trial registration: The trial is registered on clinicaltrial.gov (NCT01015625, date of registration:18/11/2009).

Keywords: breast cancer, metastatic cancer, cancer management, quality of life

\footnotetext{
* Correspondence: vesna.bjelic-radisic@helios-gesundheit.de

'Breast Unit, University Hospital Wuppertal, Heusnerstraße 40, 42283

Wuppertal, Germany

${ }^{2}$ Department of Gynecology and Obstetrics, Medical University Graz, Graz,

Austria

Full list of author information is available at the end of the article
}

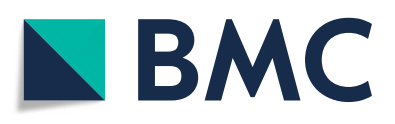

(- The Author(s). 2020 Open Access This article is licensed under a Creative Commons Attribution 4.0 International License, which permits use, sharing, adaptation, distribution and reproduction in any medium or format, as long as you give appropriate credit to the original author(s) and the source, provide a link to the Creative Commons licence, and indicate if changes were made. The images or other third party material in this article are included in the article's Creative Commons licence, unless indicated otherwise in a credit line to the material. If material is not included in the article's Creative Commons licence and your intended use is not permitted by statutory regulation or exceeds the permitted use, you will need to obtain permission directly from the copyright holder. To view a copy of this licence, visit http://creativecommons.org/licenses/by/4.0/. The Creative Commons Public Domain Dedication waiver (http://creativecommons.org/publicdomain/zero/1.0/) applies to the data made available in this article, unless otherwise stated in a credit line to the data. 


\section{Background}

Breast cancer $(\mathrm{BC})$ remains by far the most frequent type of cancer in women, with 1.7 million new cases and more than 500.000 deaths annually worldwide [1]. Despite large-scale efforts directed towards early detection, about $25 \%$ of newly diagnosed breast cancer patients have metastases at the time of diagnosis [2]. The median survival of metastatic breast cancer (MBC) patients improved significantly between 2000 and 2010 as compared to the previous decade and is expected to rise further [3]. This is particularly true for patients younger than 49 years, whose 5-year overall survival increased from $18 \%$ to $36 \%$ with an increase of median OS from 22.3 to 38.7 months. $11 \%$ of women younger than 64 years diagnosed with metastatic breast cancer between 2000 and 2004 survived longer than 10 years [3]. Treatment goals in patients with $\mathrm{MBC}$ are to prolong survival and preserve their quality of life (QoL) [4, 5].

It remains unclear whether patients presenting with $\mathrm{MBC}$ benefit from surgery $[6,7]$. It is unknown whether surgery impacts the survival outcomes of these women [6-12], or whether surgery might improve QoL by eliminating the primary tumor. In 2011 the Austrian Breast and Colorectal Study Group (ABCSG) initiated a randomized trial of primary surgery versus primary systemic therapy in women with primary synchronous $\mathrm{MBC}$ (ABCSG 28, Primary breast operation in synchronous metastasized invasive breast cancer; Posytive Trial) [13]. This study, which was halted prematurely because of a slow accrual of patients, still demonstrated that surgery provided no benefit in overall survival (OS), time to distant metastases (TTPd), or time to locoregional metastases (TTPl) [13]. Given that surgery fails to improve survival, QoL in this population becomes an important decision tool. The present report describes the QoL results of the Posytive Trial.

\section{Methods}

The ABCSG 28 trial (ClinicalTrials.gov NCT01015625) was a prospective, multicenter, randomized, phase III study in patients with primary $\mathrm{MBC}$, the primary outcomes of which have been reported [13].

The primary aim of the study was to investigate whether upfront resection of the breast tumor followed by standard radiation and systemic therapy improved median survival compared with no surgical resection. Secondary endpoints were time to distant and locoregional progression (TTPd; TTPl) and assessment of QoL. The trial randomized patients with primary operable $\mathrm{BC}$ with visceral and/or non-visceral metastases (with or without biopsy of the metastases) in 15 centres in Austria between 2011 and 2015. The patients were stratified according to grading, receptor status, HER2 status, location of metastasis (visceral vs bone-only metastases),and planned first-line therapy. The trial intended to randomize 254 patients but was stopped prematurely at 4 years because of slow recruitment. At the time recruitment was stopped the trial had enrolled 90 patients, with 45 randomised into each arm [13]. The present report describes QoL results of this trial. (Consort diagram of the patients randomized to the ABCSG28 Positive trial with QoL assessment is presented in Fig. 1.) The ABCSG 28 [13] and the present analysis of QoL data adheres to CONSORT guidelines.

The trial is listed on clinicaltrial.gov (NCT01015625) and has been approved by local ethic authorities of each centres. All patients signed informed consent.

\section{QoL assessment}

QoL was assessed with the EORTC QLQ-C30 (Version 3.0) core questionnaire [14] and the EORTC QLQ-BR23 questionnaire for breast cancer patients [15]. Patients completed the questionnaires before randomisation and every 6 months during follow-up.

The EORTC QLQ-C30 consists of 30 items measuring global health/QoL scale, functioning scales (physical, role, emotional, cognitive, and social functioning scale) and symptoms scales/items (fatigue, nausea and emesis, pain, dyspnoea, insomnia, appetite loss, constipation, diarrhoea, financial difficulties). All scales and single items range from 0 to 100 . High scores for functioning and global health/QoL scales indicate high/healthy levels of functioning/high QoL, whereas high scores for a symptom scales/items indicate a high level of symptoms/ problems [14]. The 23-item EORTC QLQ BR23 contains five multi-item scales to assess body image, sexual functioning, systemic therapy side effects, arm symptoms and breast symptoms and single items to assess sexual enjoyment, future perspective and upset by hair loss. The multi-item scales and single items are divided in to two groups, namely functional scales: body image, sexual functioning, sexual enjoyment and future perspective and symptom scales/items: systemic therapy side effects, breast symptoms, arm symptoms and upset by hair loss [15]. All scales and single items range from 0 to 100 . A high score for all functioning scales indicates high/ healthy level of functioning/high QoL, whereas a high score for a symptom scale/items indicates a high level of symptoms/problems.

\section{Statistical analysis}

The EORTC QLQ-C30 and EORTC QLQ BR23 scales and single items were linearly transformed to 0-100 and analysed according to the recommendations of the EORTC QoL Group [16]. Differences of at least 10 points on the scales/items were defined as the threshold for minimum of clinically significant difference [17]. All QoL analyses were based on the QoL-evaluable population 


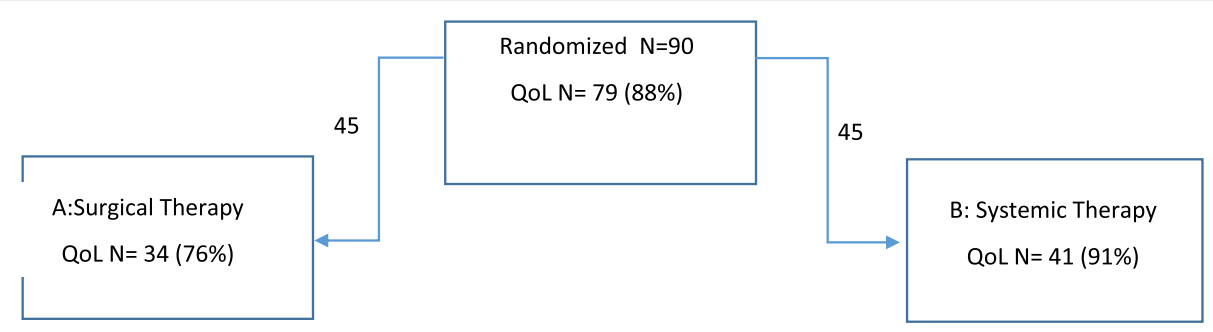

Fig. 1 Consort diagram of the patients randomised to the ABCSG-28 Positive trial with QoL assessment

i.e. patients in the intent-to-treat population with a baseline QOL assessment. Questionnaire completion rates were calculated for all patients per assessment time and per treatment arm. Completion rates were summarized by visit.

At that time only 90 patients were enrolled, 45 in each arm. Thus, the study is underpowered and needs to be interpreted in an explorative manner.

Patient characteristics between patient with and without QOL assessment were tested with Chi square / Fischer Test. The main QOL objective was to test whether Surgical Arm leads to improved QOL when compared with Systematic Therapy Arm, based on the Global health/QOL scale of the QLQ-C30. The primary analysis was performed by fitting a linear mixed model with treatment, a (linear) time effect, a time-treatment interaction as fixed effects and patient specific random effect on QoL-evaluable population. Treatment, time, treatment by time, and baseline were covariates for the model. A restricted maximum likelihood method assuming an unstructured covariance matrix was used.

Additional analyses were done by age, site of metastases, and type of primary systemic therapy (chemotherapy vs. other) as covariates. No adjustments were made for multiple comparisons.

Baseline Global health status/QoL, and physical functioning scale scores were split at the median to yield 'good' and 'poor' scores.

All analyses were conducted using Statistical Analysis System software (SAS Institute, Cary, NC) for Windows (Microsoft Corp., Redmond, WA). All P values are twosided unless stated otherwise.

\section{Results}

Between 2011 and 201590 patients were randomized at 15 centers, 45 patients into each arm. 79 (88\%) patients completed QoL assessment at least at baseline. 34 (76\%) patients in the surgery arm and 41 (91\%) in the nosurgery arm were included in the QoL analyses. (Table 1) A total of 289 QoL questionnaires were analysed $79(88 \%)$ at baseline and 60 (76\%), 54 (73\%), 38 (56\%), 32 (52\%), at $6,12,18$ and 24 months, respectively. QoL analysis covered the results of the five assessment time points (baseline and 6,12,18 and 24 months' follow-up).
Except for tumour size, demographic and clinical characteristics in patients for whom QoL data were available and in those for whom they were not were similar (Table 2). Median age was 62.8 years and similar in both groups (61.7 vs 63.9).

Survival data have been reported previousl y[13]. Surgery did not provide an OS benefit (34.6 months vs 54.8 months, $p=0.267$; HR $0.691 ; 95 \%$ CI $0.358-1.333$ ) or TTPd and TTPl ( HR 0.598, $p=0.0668$; HR 0.933, $p=$ 0.882 )[13] (Fig. 2a and b).

\section{QoL assessment as predictor for OS and TTPd}

In the univariate and multivariate analyses the Global health status/QoL and physical functioning scales were predictors for overall OS. Patients with a higher score of global health status/QoL and higher score of physical functioning lived longer (HR 0.984; $p=0.0250$, HR 0.984; $p=0.0225$; HR $0.988 p=0.0355$, HR0.988; $p=0.0355$ ) (Fig. 3a; b, Table 3). Although not statistically significant, patients with a higher score on the scale future perspective showed a tendency to longer OS in the univariate analyses (HR 0.987; $p=0.0510$ ). In the univariate analyses scales Global health status/QoL and social functioning scale were a predictor for a longer TTPd (HR 0.985, $p=0.0244 ;$ HR 0.989, $p=0.0140$ )( Table 4).

In the univariate and multivariate analyses, the scale future perspective was a predictor for longer TTPd (HR 0.988, $p=0.020$; HR 0.982, $p=0.0123$ ) (Table 4). In the multivariate analyses scale breast symptoms was a predictor for TTPd (HR 0.933, $p=0.0438$ )( Table 4).

\section{QoL assessment by therapy arm}

Details of the systemic and local therapy in the surgical and no surgical arm are listed in the Table 2. There were no statistically significant differences in any of the scales of the QLQ-C30 and QLQ-BR23 questionnaires between the two groups over the time. (Table 5) Figure 4 presented QoL scale with statistically significant change (improvement or worsening) over the time in both groups.

\section{QLQ C30}

\section{Global Health Status/QoL}

At baseline, clinically relevant ( $>10$ points differences) differences favouring the no-surgery arm were found in 
Table 1 Demographic and clinical characteristics of patients randomized in the ABCSG 28 study, $n=90$

\begin{tabular}{|c|c|c|c|c|c|}
\hline \multirow{2}{*}{$\begin{array}{l}\text { Category } \\
\text { Number of patients }\end{array}$} & \multicolumn{2}{|c|}{ In Qol n(\%) } & \multicolumn{2}{|c|}{ no QoLn(\%) } & \multirow[t]{2}{*}{ P-value } \\
\hline & & & & & \\
\hline & 79 & 100.0) & 11 & 100.0) & \\
\hline \multicolumn{6}{|l|}{ Menopause Status } \\
\hline Perimenopausal & 1 & (1.3) & . & . & 1.0 \\
\hline Postmenopausal & 69 & $(87.3)$ & 9 & $(81.8)$ & \\
\hline Premenopausal & 9 & $(11.4)$ & 2 & $(18.2)$ & \\
\hline \multicolumn{6}{|l|}{ T-stage } \\
\hline CT1 & 15 & $(19.0)$ & 2 & $(18.2)$ & 0.0498 \\
\hline cT2 & 33 & $(41.8)$ & 7 & $(63.6)$ & \\
\hline cT3 & 12 & $(15.2)$ & 1 & (9.1) & \\
\hline cT4 & 16 & $(20.3)$ & . & . & \\
\hline Missing & 3 & (3.8) & 1 & $(9.1)$ & \\
\hline \multicolumn{6}{|l|}{$\mathrm{N}$-stage } \\
\hline cNO & 18 & $(22.8)$ & 2 & $(18.2)$ & 0.4261 \\
\hline $\mathrm{cN} 1$ & 34 & $(43.0)$ & 7 & (63.6) & \\
\hline $\mathrm{cN} 2$ & 9 & (11.4) & . & . & \\
\hline cN3 & 6 & (7.6) & & & \\
\hline Missing & 12 & $(15.2)$ & 2 & $(18.2)$ & \\
\hline \multicolumn{6}{|l|}{ Grading } \\
\hline G1 & 5 & (6.3) & 2 & $(18.2)$ & 0.6282 \\
\hline G2 & 44 & $(55.7)$ & 4 & (36.4) & \\
\hline G3 & 24 & (30.4) & 4 & $(36.4)$ & \\
\hline Gx & 3 & (3.8) & 1 & (9.1) & \\
\hline Missing & 3 & (3.8) & . & . & \\
\hline \multicolumn{6}{|l|}{ HER2 } \\
\hline FISH amplif./IHC+++ & 15 & (19.0) & 5 & $(45.5)$ & 0.4475 \\
\hline Negative & 63 & $(79.7)$ & 6 & $(54.5)$ & \\
\hline Missing & 1 & (1.3) & . & . & \\
\hline \multicolumn{6}{|l|}{ Hormone Status } \\
\hline any positive & 65 & $(82.3)$ & 8 & $(72.7)$ & 1.0 \\
\hline Negative & 14 & $(17.7)$ & 3 & $(27.3)$ & \\
\hline \multicolumn{6}{|l|}{ Tumor Subtype } \\
\hline Basal Type & 8 & $(10.1)$ & . & . & 0.8181 \\
\hline HER2 Type & 15 & $(19.0)$ & 5 & $(45.5)$ & \\
\hline Luminal A & 41 & $(51.9)$ & 5 & $(45.5)$ & \\
\hline Luminal B & 11 & $(13.9)$ & 1 & (9.1) & \\
\hline Missing & 4 & (5.1) & . & . & \\
\hline
\end{tabular}

Legends: QoL- Quality of Life

the Global Health Status/QoL scale (mean, 47.8 vs 61.6) (Table 5). These preferences disappeared at the first follow-up (6 months) and were not seen at further time points. Over time (up to 24 months follow up) patients in both arms had a clinically relevant and statistically
Table 2 Systemic and local therapy of patients participated in the QoL study

\begin{tabular}{ll}
\hline $\begin{array}{l}\text { Arm A } \\
\text { Surgical therapy } \\
N=37\end{array}$ & $\begin{array}{l}\text { Arm B } \\
\text { No surgical therapy } \\
N=42\end{array}$ \\
\hline$N(\%)$ & $N(\%)$
\end{tabular}

First line therapy

\begin{tabular}{llll} 
Any CTX no Taxane & $6(16.2)$ & $5(11.9)$ & \\
Any CTX with Taxane & $4(10.8)$ & $10(23.8)$ & \\
Endocrine therapy & $27(73.0)$ & $27(64.3)$ & 0.308 \\
Radiotehrapy & & & \\
Breast/Chest wall & $9(22.0)$ & $2(4.7)$ & 0.020 \\
Metastases & $11(26.8)$ & $8(18.6)$ & 0.268 \\
Surgery & & & 0.618 \\
Metastases & $1(2.4)$ & $3(7.0)$ & \\
\hline
\end{tabular}

*Fischer exact test

CTX-Chemotherapy

significant improvement on the scale global health status $(p=0.003)$ (Fig. 4a)

\section{Functional scales of the QLQ-C30}

There were no statistically significant differences in any of the five functional scales of the QLQ-C30 [physical, role, emotional, cognitive and social functioning] at baseline, as well as over time. Patients reported significant improvement on the scale emotional functioning in both arms over time (Fig. 4b). In the surgical arm this improvement was clinically relevant. Cognitive functioning decreased over time in both groups, clinically relevant and statistically significant in the primary surgery arm and statistically significant without clinical relevance in the non-surgery arm (Fig. 4c).

\section{Symptom scales/Items of the EORTC QLQ-C30}

The mean scores of symptoms scales/items at baseline and during follow-up remained on the lower part of the $0-100$ scale. Statistically significant worsening was found on the scale dyspnoea $(p=0.025)$, but this difference was without clinical relevance in both arms (Fig. 4d).

Over time patients reported more financial problems in both arms (Fig. 4e).

\section{Functional scales of the QLQ-BR23}

In both arms statistically significant and clinically relevant improvement was seen over time on the scale future perspective ( $p=0.009)$ (Fig. 4f). In contrast, patients in both arms reported worsening symptoms on the body image scale, clinically relevant in the surgery arm $(p=$ 0.017 , Fig. 4g). At baseline women in the non-surgery arm reported a statistically significant and clinically relevant better mean score in the functional scale future perspective (mean 45.0 vs 21.4). In the following visits 
A.

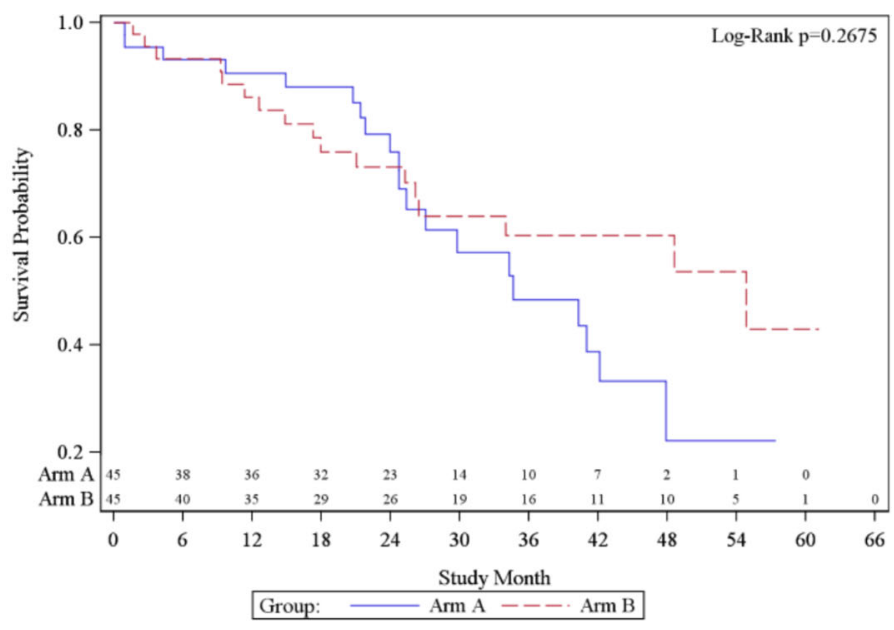

B.

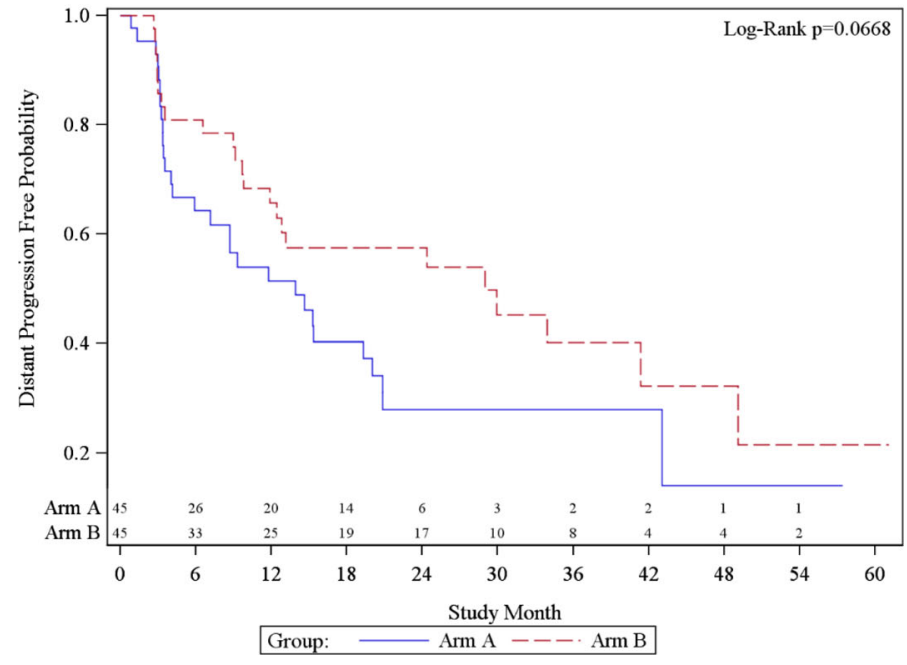

Legend:

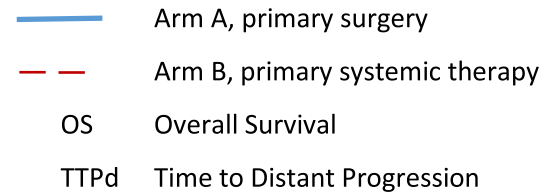

Fig. 2 Kaplan-Meier Plot for OS and TTPd. A. OS. B. TTPd. —_Arm A, primary surgery. — - Arm B, primary systemic therapy. OS Overall Survival. TTPd Time to Distant Progression

there were no differences in any of the functional scales between two arms (Table 5).

\section{QLQ-BR23 symptoms scales}

In both arms, statistically significant and clinically relevant improvement was seen over time on the breast symptoms scale ( $p=0.006$, Fig. 4 h). Symptom worsening was found on the scales symptoms of the systemic therapy and hair loss, but these differences were without clinical relevance in both arms. $(p<0.001$, Fig. $4 \mathrm{i}, \mathrm{j})$

\section{QoL assessment by age}

The median age of our study population was $64 \mathrm{y}$ (range $23 y-85 y) .64 .5 \%$ of women were older than 60 years and 
A.

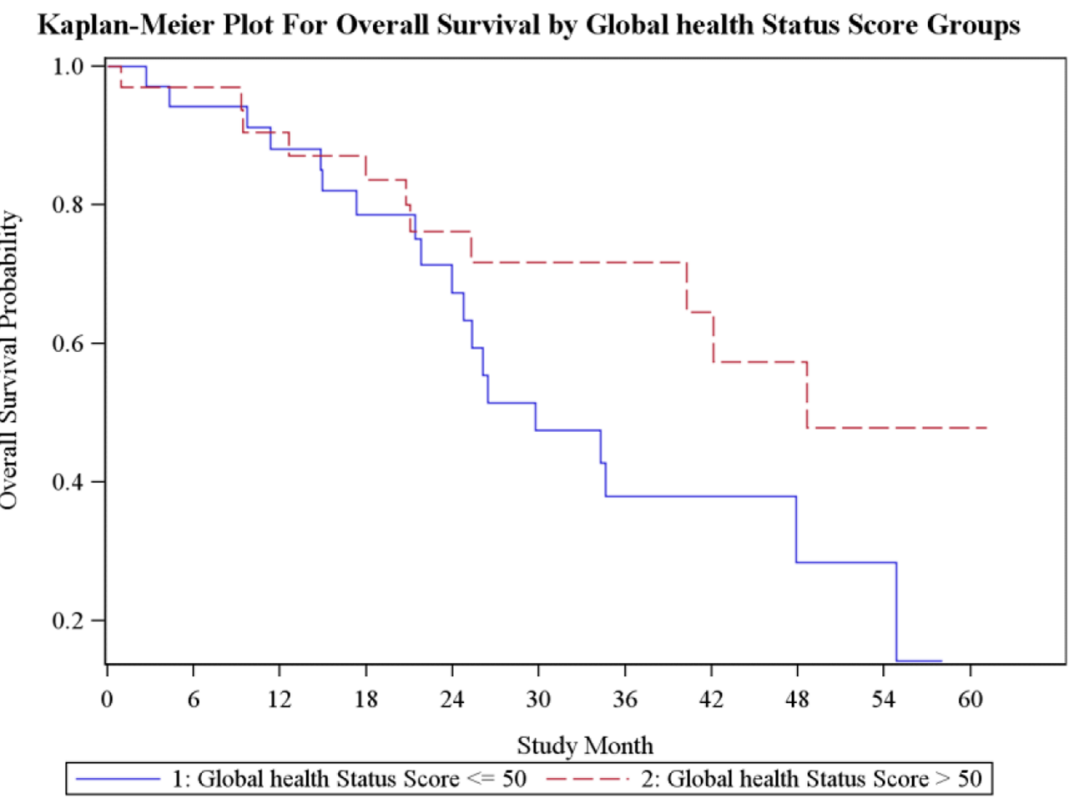

B.

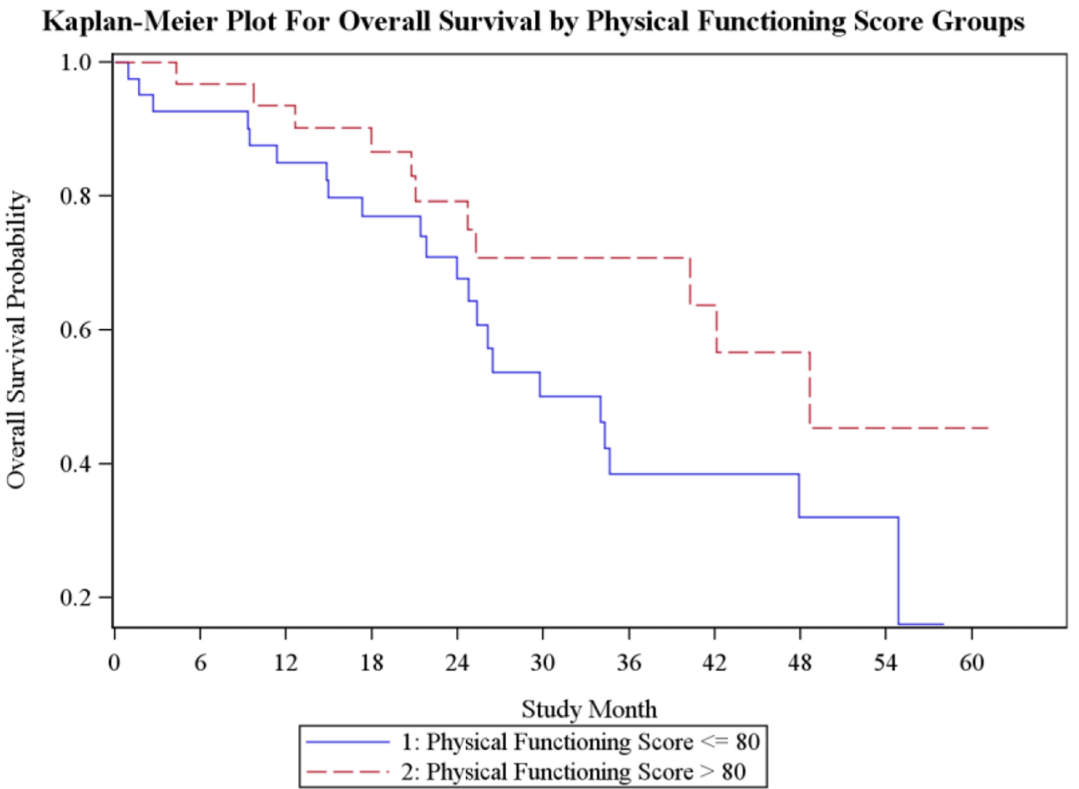

Fig. 3 Kaplan-Meier Plot for OS by Global Health Status and Physical Fuctioning of the EORTC QLQ C30Legends: OS - Overall Survival

only $14 \%$ were premenopausal. We compared women < 60 and $\geq 60$ years to assess a possible impact of age on QoL. There were no differences in the functional or symptomatic scales of the QLQ-C30 and QLQ -BR 23 between the two groups of women except in physical functioning scale (EORTC -QLQC30) and sexual functioning scale (EORTC BR 23). As expected, younger women had a statistically significant and clinical relevant better mean score of the physical functioning scale $(p=$ $0.039)$ and sexual functioning score $(p=0.024)$ (Table 6). 
Table 3 QoL Score as predictor for OS (univariate and multivariate analyse)

\begin{tabular}{|c|c|c|c|c|c|c|c|c|}
\hline & Univar & nalyse & & & Multiv & Analyse & & \\
\hline & $\mathrm{HR}$ & 95\%-LL & 95\%-UL & Cox P-value & $\mathrm{HR}$ & 95\%-LL & 95\%-UL & Cox P-value \\
\hline Physical Functioning & 0.988 & 0.977 & 0.999 & 0.0355 & 1.016 & 0.983 & 1.051 & 0.3523 \\
\hline Role Functioning & 0.993 & 0.984 & 1.001 & 0.0988 & 0.995 & 0.969 & 1.021 & 0.6966 \\
\hline Emotional Functionin & 1.000 & 0.987 & 1.014 & 0.9511 & 1.031 & 1.003 & 1.059 & 0.0293 \\
\hline Cognitive Functionin & 0.999 & 0.980 & 1.018 & 0.9206 & 0.999 & 0.961 & 1.039 & 0.9723 \\
\hline Social Functioning & 0.996 & 0.986 & 1.006 & 0.4450 & 0.996 & 0.978 & 1.015 & 0.6955 \\
\hline Global health status & 0.984 & 0.970 & 0.998 & 0.0250 & 0.960 & 0.932 & 0.990 & 0.0088 \\
\hline Fatigue & 1.006 & 0.995 & 1.016 & 0.2874 & 1.002 & 0.973 & 1.031 & 0.9111 \\
\hline Nausea / Vomiting & 1.012 & 0.996 & 1.028 & 0.1382 & 1.017 & 0.985 & 1.049 & 0.3077 \\
\hline Pain & 1.007 & 0.999 & 1.016 & 0.0955 & 1.018 & 0.992 & 1.045 & 0.1828 \\
\hline Dyspnoea & 1.007 & 0.994 & 1.020 & 0.2738 & 1.018 & 0.997 & 1.038 & 0.0882 \\
\hline Insomnia & 1.003 & 0.992 & 1.014 & 0.6502 & 0.994 & 0.979 & 1.010 & 0.4795 \\
\hline Appetite loss & 1.007 & 0.996 & 1.017 & 0.2027 & 0.996 & 0.967 & 1.026 & 0.7874 \\
\hline Constipation & 1.002 & 0.990 & 1.013 & 0.7756 & 0.986 & 0.966 & 1.005 & 0.1494 \\
\hline Diarrhoea & 0.994 & 0.974 & 1.014 & 0.5714 & 0.997 & 0.971 & 1.024 & 0.8285 \\
\hline Financial Problems & 0.990 & 0.971 & 1.009 & 0.2845 & 0.977 & 0.950 & 1.004 & 0.0922 \\
\hline BR Body image & 0.992 & 0.978 & 1.006 & 0.2724 & 0.997 & 0.978 & 1.016 & 0.7507 \\
\hline BR Sexual functioning & 0.993 & 0.976 & 1.009 & 0.3856 & 0.995 & 0.976 & 1.014 & 0.5827 \\
\hline BR Future perspective & 0.987 & 0.975 & 1.000 & 0.0510 & 0.990 & 0.974 & 1.007 & 0.2678 \\
\hline BR Systemic therapy & 1.013 & 0.998 & 1.029 & 0.0888 & 1.008 & 0.977 & 1.040 & 0.6281 \\
\hline BR Breast symptoms & 1.005 & 0.989 & 1.022 & 0.5249 & 1.007 & 0.986 & 1.027 & 0.5268 \\
\hline BR Arm symptoms & 1.008 & 0.990 & 1.027 & 0.3686 & 0.996 & 0.973 & 1.020 & 0.7320 \\
\hline BR Hair loss & 0.988 & 0.977 & 0.999 & 0.0355 & 0.982 & 0.931 & 1.036 & 0.5133 \\
\hline BR Sexual enjoyment & 0.993 & 0.984 & 1.001 & 0.0988 & 0.997 & 0.978 & 1.016 & 0.7507 \\
\hline
\end{tabular}

Legends: OS Overall Survival, HR Hazard ratio

\section{QoL assessement by type of systemic therapy}

\section{(chemotherapy vs. other, with or without surgery)}

Overall, 79 women completed baseline QoL assessment and received chemotherapy (CTX) $(N=25)$ or endocrine therapy $(N=54)$ as first-line systemic therapy. Women who received CTX reported baseline clinically better mean score on the scale physical functioning of the EORTC QLQC30 (Table 8). Over time those patients had statistically significant more diarrhoea $(p=0.0014)$ (Table 7).

\section{Qol by site of metastases}

Twenty-nine women with bone metastases only and 46 women with visceral \pm bone metastases completed QoL assessments at baseline. Interestingly, women with bone metastases only reported worse physical functioning (59.8 vs $77.9 ; p=0.0079)$ and role functioning (55.9 vs $74.8 ; p=0.0412)$ on the functional scales of the QLQC30, as well as more pain (mean 52.0 vs 24.6; $p=0.0066$ ) compared to women with visceral \pm bone metastases. All differences were statistically significant and clinical relevant. Differences at baseline were not visible anymore until the last visit at 24 months (Table 8).

\section{Discussion}

Treatment of women with MBC aims to prolong survival and improve or maintain QoL [4]. Our results indicate that primary surgery does not appear to improve QoL in patients presenting with MBC. QoL assessments in these women are critical and many phase 3 trials in this population include QoL as a primary or secondary endpoint [18]. The ABCSG 28 is the third randomised trial evaluating the role of primary surgery in women with stage IV $\mathrm{BC}$, but the first to report the impact of primary surgery prior to systemic therapy versus primary systemic therapy on QoL [13]. Two previous randomised trials [7, 12] of surgery vs. no surgery described oncologic outcomes; QoL data from one of these trials have been presented in abstract form [19].

Our trial, which was halted prematurely, indicated that primary surgery does not improve OS, TTPd or TTPl in women presenting with MBC [13]. This makes QoL outcomes all the more important. Our results indicate that 
Table 4 QoL Score as predictor for TTPd (univariate and multivariate analyse)

\begin{tabular}{|c|c|c|c|c|c|c|c|c|}
\hline & \multicolumn{4}{|c|}{ Univariate Analyse } & \multicolumn{4}{|c|}{ Multivariate Analyse } \\
\hline & $\mathrm{HR}$ & 95\%-LL & 95\%-UL & Cox P-value & $\mathrm{HR}$ & 95\%-LL & 95\%-UL & Cox P-value \\
\hline Physical Functioning & 0.995 & 0.985 & 1.006 & 0.3855 & 1.006 & 0.978 & 1.034 & 0.6704 \\
\hline Role Functioning & 0.995 & 0.987 & 1.004 & 0.2671 & 1.010 & 0.988 & 1.034 & 0.3741 \\
\hline Emotional Functioning & 0.999 & 0.986 & 1.011 & 0.8220 & 1.018 & 0.996 & 1.041 & 0.1006 \\
\hline Cognitive Functioning & 0.993 & 0.976 & 1.009 & 0.3852 & 1.005 & 0.979 & 1.031 & 0.7245 \\
\hline Social Functioning & 0.989 & 0.979 & 0.998 & 0.0140 & 0.986 & 0.969 & 1.003 & 0.1057 \\
\hline Global health status & 0.985 & 0.973 & 0.998 & 0.0244 & 0.983 & 0.961 & 1.005 & 0.1313 \\
\hline Fatigue & 1.003 & 0.993 & 1.013 & 0.6083 & 1.011 & 0.988 & 1.035 & 0.3465 \\
\hline Nausea / Vomiting & 1.010 & 0.994 & 1.026 & 0.2174 & 1.009 & 0.978 & 1.040 & 0.5811 \\
\hline Pain & 1.006 & 0.998 & 1.015 & 0.1443 & 1.015 & 0.993 & 1.037 & 0.1797 \\
\hline Dyspnoea & 1.007 & 0.996 & 1.018 & 0.1908 & 1.015 & 0.998 & 1.032 & 0.0829 \\
\hline Insomnia & 1.000 & 0.991 & 1.009 & 0.9839 & 0.999 & 0.986 & 1.011 & 0.8211 \\
\hline Appetite loss & 1.000 & 0.990 & 1.010 & 0.9466 & 0.991 & 0.969 & 1.013 & 0.4189 \\
\hline Constipation & 0.998 & 0.987 & 1.009 & 0.7022 & 0.986 & 0.969 & 1.003 & 0.0992 \\
\hline Diarrhoea & 0.998 & 0.983 & 1.013 & 0.8056 & 0.999 & 0.979 & 1.018 & 0.8917 \\
\hline Financial Problems & 1.005 & 0.993 & 1.016 & 0.4073 & 0.998 & 0.984 & 1.013 & 0.8026 \\
\hline BR Body image & 0.999 & 0.985 & 1.013 & 0.8986 & 1.001 & 0.985 & 1.017 & 0.8999 \\
\hline BR Sexual functioning & 0.992 & 0.979 & 1.006 & 0.2574 & 1.001 & 0.986 & 1.015 & 0.9242 \\
\hline BR Future perspective & 0.988 & 0.978 & 0.999 & 0.0250 & 0.982 & 0.968 & 0.996 & 0.0123 \\
\hline BR Systemic therapy & 1.000 & 0.984 & 1.017 & 0.9664 & 1.010 & 0.984 & 1.036 & 0.4762 \\
\hline BR Breast symptoms & 1.008 & 0.994 & 1.023 & 0.2611 & 1.021 & 1.001 & 1.041 & 0.0438 \\
\hline BR Arm symptoms & 0.993 & 0.973 & 1.012 & 0.4568 & 0.994 & 0.973 & 1.017 & 0.6238 \\
\hline BR Hair loss & 0.952 & 0.899 & 1.010 & 0.1014 & 0.933 & 0.872 & 0.998 & \\
\hline BR Sexual enjoyment & 1.010 & 0.984 & 1.038 & 0.4525 & 1.001 & 0.985 & 1.017 & 0.8999 \\
\hline
\end{tabular}

Legends: TTPd- time to distant progression; QoL: Quality of life

global health status, physical functioning, social functioning, and future perspective were predictors for OS and/or TTTd. QoL outcomes as predictors for OS in BC have already previously been described in early $\mathrm{BC}$, with the scale future perspective also being a predictor for OS in that setting [20]. This indicates that QoL results, especially the robust scale global health/QoL and future perspective, could be used as an additional marker for prediction of OS and TTTd.

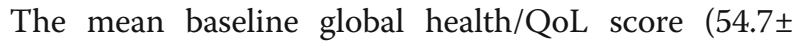
26.1) of patients in our study is in line with reference values $(60.2 \pm \mathrm{SD} 25.5)$ for recurrent/ metastatic BC [21]. Although patients in the non-surgery arm reported a higher mean score on the Global Health Score/QoL at baseline, this difference disappeared at the first followup visit at 6 months after randomization and did not reappear later. The difference at baseline was caused by a rather low score in the surgery arm, while the score in the nonsurgery arm was in line with reference data and other studies [21, 22]. These differences at baseline could be the result of the relatively small number of patients in the surgical arm who completed QoL assessment at baseline. Assessment at the following time point showed no differences between the arms, similar to the results reported by Rajendra et al [22]. On the other hand, the difference may reflect a short term impact of the surgery on QoL and global health score.

Patients in both arms of our study showed clinically significant improvements on the global health/QoL scale as well as on the functional scales emotional functioning and future perspectives. Emotional symptoms in MBC patients are associated with physical symptoms such as pain, insomnia and fatigue and improvement of emotional functioning is clearly important [20, 23-28]. In our trial, insomnia and fatigue were the most severe symptoms at baseline in both arms and remain unchanged over the time.

Patients without surgery reported clinically relevant fewer breast and arm symptoms at the 6 months, indicating that local surgery causes symptoms and morbidity that persist for at least at 6 months. Patients without surgery reported better cognitive function than those with surgery, and the score on the cognitive functioning scale was stable from baseline to the 24-month follow- 


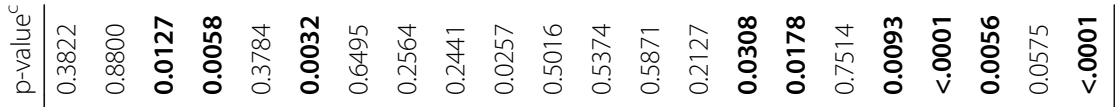

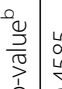

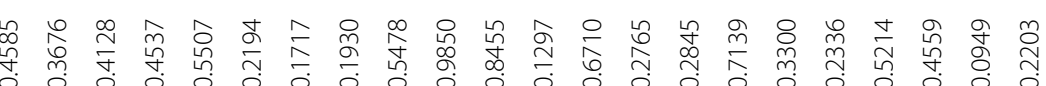

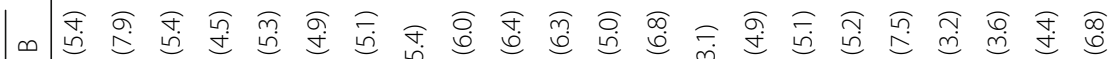

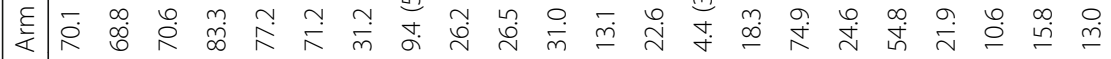

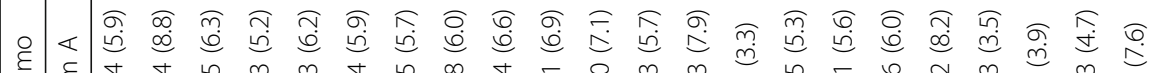

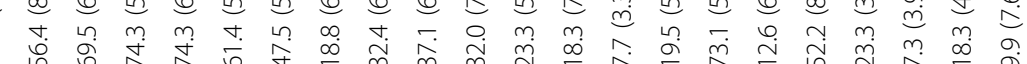

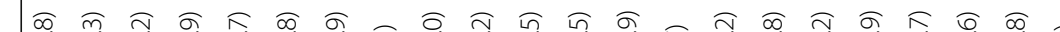

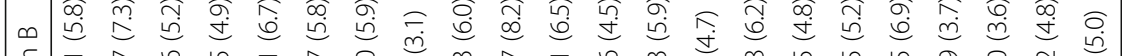

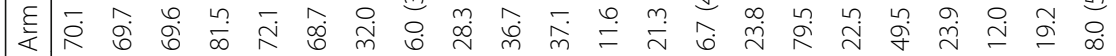

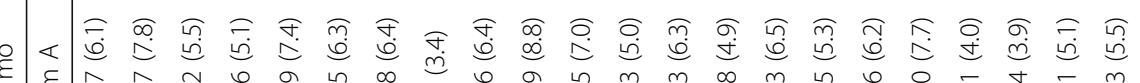

崔|

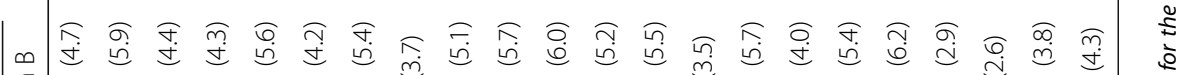

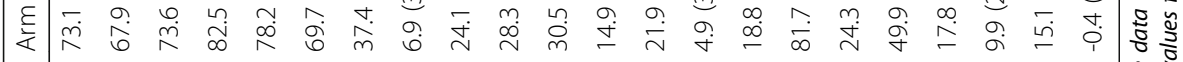

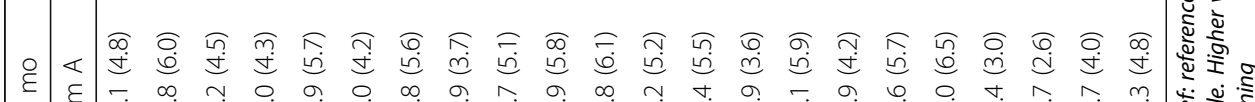

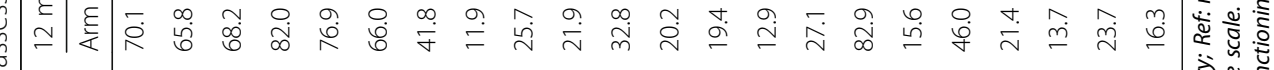

要

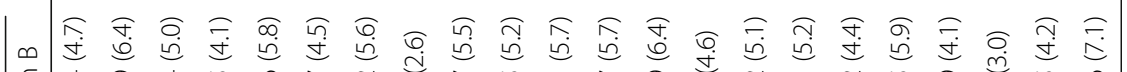

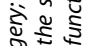

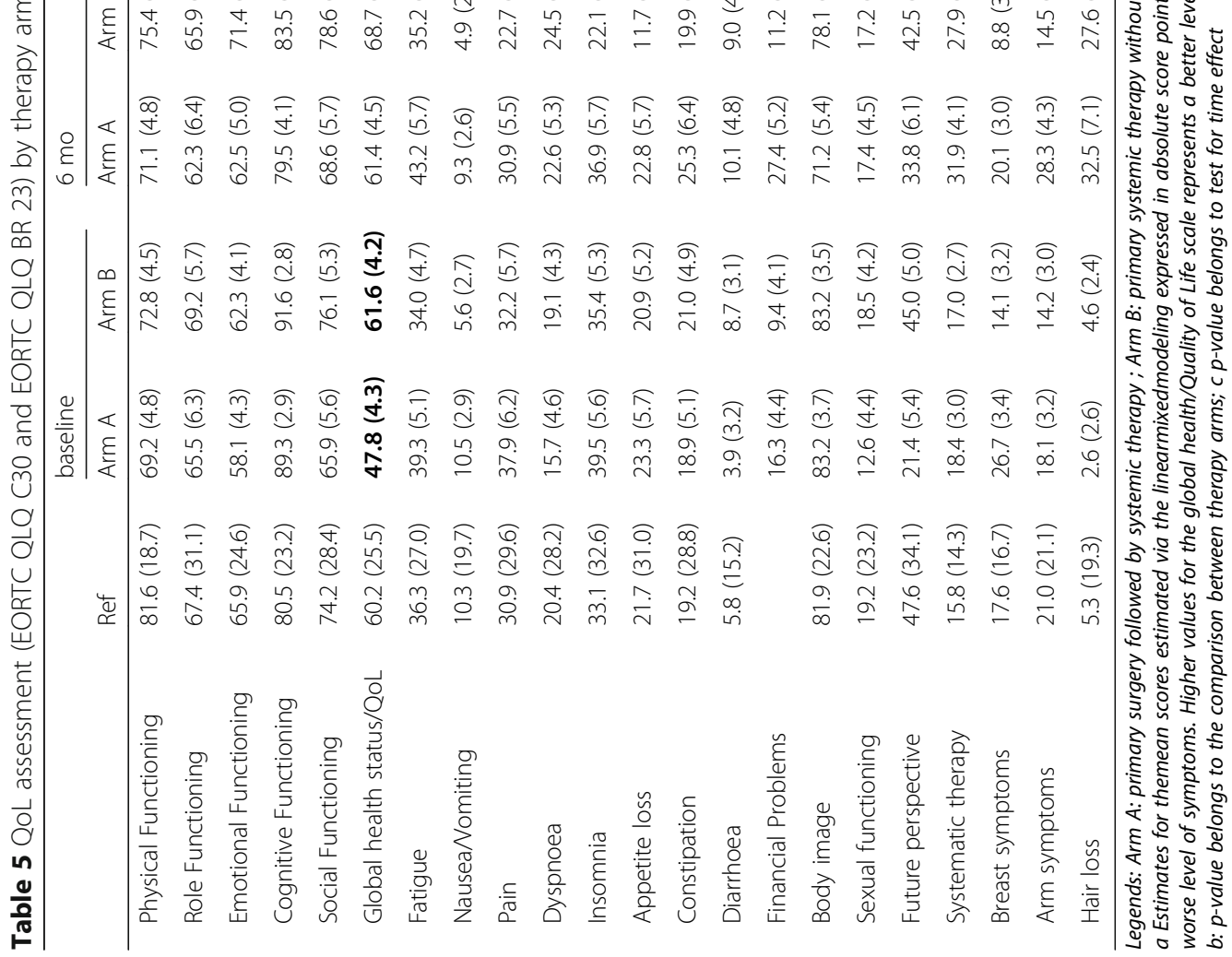




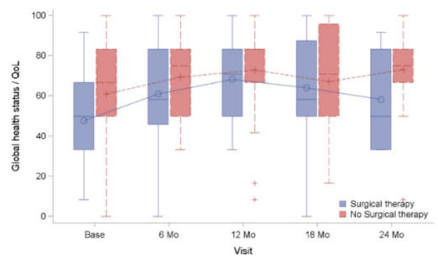

4a.Global health status (C30)

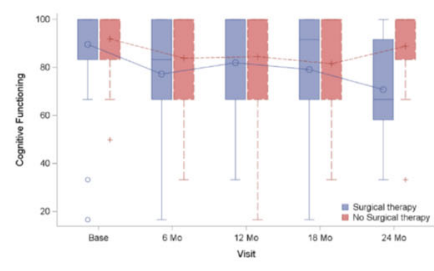

4c. Cognitive Functioning (C30)

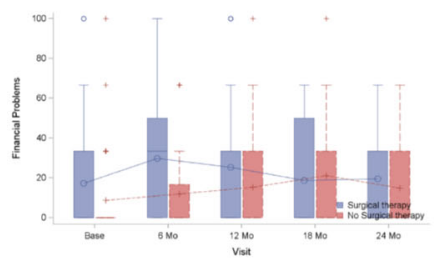

4e. Financial problems (C30)

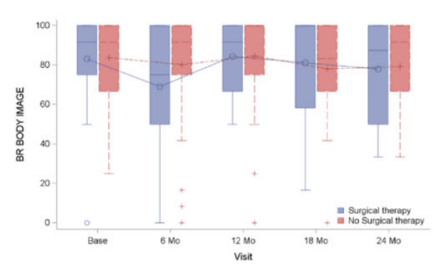

4g. Body image (BR 23)

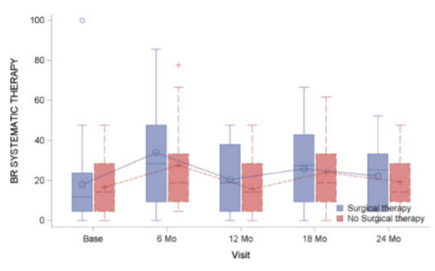

4i. Systemic therapy (BR23)

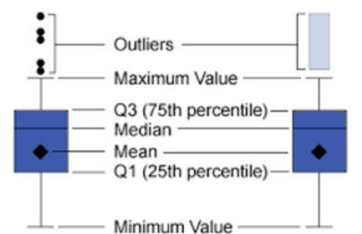

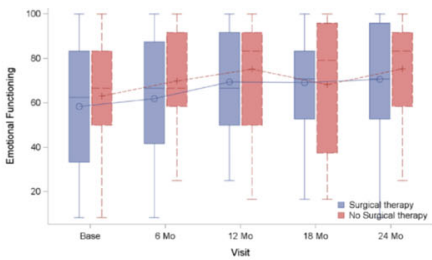

4b.Emotional Functioning (C30)

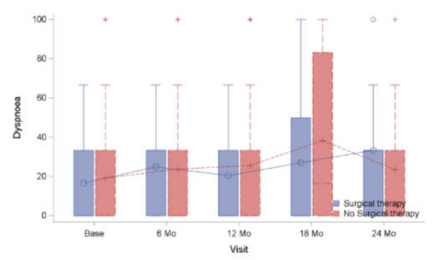

4d. Dyspnoa (C 30)

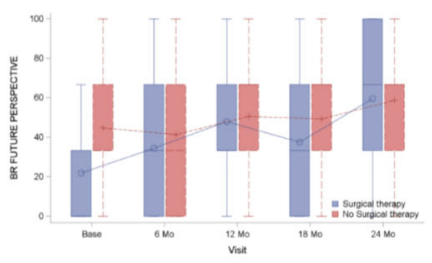

4f.Future perspective (BR 23)

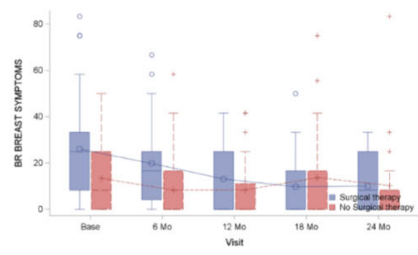

4h. Breast symptoms (BR23)

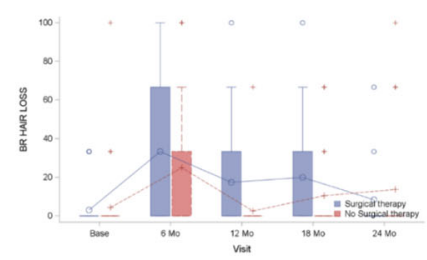

4j. Hair loss (BR 23)

4k. Box Plot Legende

Fig. 4 (See legend on next page.) 
(See figure on previous page.)

Fig. 4 QoL scales (EORTC QLQ C30 and EORTC QLQ BR 23) by therapy arm with statistical significant changes over the time. Legende.4a Global health status (C30) $p=0.003$; 4b. Emotional Functioning (C30) p =0.013; 4c. Cognitive Functioning (C30) p=0.006; 4d. Dyspnoea (C 30) p=0.026; 4e. Financial problems (C30) $p=0.031$; 4f.Future perspective (BR 23) $p=0.009 ; 4 \mathrm{~g}$. Body image (BR 23) $p=0.018$; 4h. Breast symptoms (BR23). $p=0.006 ; 2 i$. Systemic therapy (BR23) $p<0.0001$; 4j. Hair loss (BR 23) $p<0.0001$; 4k. Box Plot Legende: $\bigcirc$ Mean value therapy arm A -Surgical therapy; + mean value thearpy arm B- no surgical therapy

up. In contrast, in the surgery group cognitive function score decreased over time by more than 10 points, indicating clinically significant worsening. The reason for this is unclear. Hermelink et al [29]. described cognitive impairment in BC patients depending on therapy [chemotherapy vs no chemotherapy] and this was intertwined with posttraumatic syndrome after receiving the diagnosis [29]. Sato et al. looked at the impact of BC surgery on cognitive function and found alterations in brain structure shortly after surgery, particularly in the thalamus, which may be associated with attentional dysfunction [30]. It may however be far-fetched to relate our observation to the immediate effects of the surgical procedure and or anaesthesia.

Analyses of QoL according to age [<60y vs $\geq 60 \mathrm{y}]$ showed that younger women had a higher score on the sexual functioning scale as well as on the physical functioning scale. These results are as expected.

Patients receiving chemotherapy as first-line therapy reported better physical functioning at baseline than patients receiving other systemic treatment. It is however likely that a good baseline performance status in these patients contributes to the selection of patients and decision for chemotherapy.

Table 6 QoL assessment (EORTC QLQ C30 and EORTC QLQ BR 23) by age and assessment time (Mean scores and standard errors)

\begin{tabular}{|c|c|c|c|c|c|c|c|c|c|c|c|}
\hline \multirow[b]{2}{*}{ QOL domain } & \multicolumn{2}{|l|}{ Baseline } & \multicolumn{2}{|l|}{$6 \mathrm{Mo}$} & \multicolumn{2}{|l|}{$12 \mathrm{Mo}$} & \multicolumn{2}{|l|}{$18 \mathrm{Mo}$} & \multicolumn{2}{|l|}{$24 \mathrm{Mo}$} & \multirow[b]{2}{*}{$p$-Value } \\
\hline & $<60$ & $>=60$ & $<60$ & $>=60$ & $<60$ & $>=60$ & $<60$ & $>=60$ & $<60$ & $>=60$ & \\
\hline Physical Functioning & $75.9(5.5)$ & $68.5(4.0)$ & $78.6(5.7)$ & $70.5(4.1)$ & $79.9(5.7)$ & $67.8(4.0)$ & $79.6(7.0)$ & $62.8(4.9)$ & $80.0(6.8)$ & $61.0(4.6)$ & 0.0390 \\
\hline Role Functioning & $71.7(7.1)$ & $65.3(5.2)$ & $64.7(7.8)$ & $63.9(5.6)$ & $73.8(7.4)$ & $64.1(5.0)$ & $77.6(8.9)$ & $58.4(6.2)$ & $71.6(10.5)$ & $59.2(7.1)$ & 0.2148 \\
\hline Emotional Functioning & $58.8(5.0)$ & $61.1(3.7)$ & $60.0(6.0)$ & $71.0(4.4)$ & $73.4(5.5)$ & $70.4(3.8)$ & $74.2(6.2)$ & $64.6(4.4)$ & $71.1(7.3)$ & $69.6(4.9)$ & 0.9035 \\
\hline Cognitive Functioning & $87.7(3.3)$ & $92.0(2.5)$ & $77.6(4.9)$ & $83.8(3.5)$ & $83.9(5.3)$ & $82.0(3.6)$ & $85.2(5.8)$ & $77.9(4.1)$ & $86.8(6.0)$ & $76.6(4.0)$ & 0.5600 \\
\hline Social Functioning & $65.0(6.5)$ & $74.6(4.8)$ & $67.2(7.0)$ & $77.0(5.0)$ & $82.2(7.1)$ & $76.2(4.7)$ & $75.8(8.6)$ & $69.8(5.9)$ & $80.9(7.2)$ & $73.5(4.8)$ & 0.7279 \\
\hline Global health status / QoL & $57.3(5.2)$ & $53.9(3.8)$ & $60.3(5.4)$ & $67.7(4.0)$ & $73.5(5.3)$ & $65.8(3.5)$ & $78.0(7.0)$ & $60.4(4.9)$ & $69.5(6.8)$ & $66.3(4.7)$ & 0.3342 \\
\hline Fatigue & $30.8(5.8)$ & $39.8(4.3)$ & $37.4(6.8)$ & $39.9(5.0)$ & $30.6(6.6)$ & $43.5(4.6)$ & $23.6(7.1)$ & $42.2(5.0)$ & $31.1(7.1)$ & $42.0(4.8)$ & 0.1158 \\
\hline Nausea / Vomiting & $10.7(3.4)$ & $6.3(2.5)$ & $10.0(3.1)$ & $5.4(2.2)$ & $7.0(4.7)$ & $10.7(3.1)$ & $9.8(4.0)$ & $5.4(2.8)$ & $21.9(7.5)$ & $11.3(5.1)$ & 0.3712 \\
\hline Pain & $32.5(7.2)$ & $36.2(5.2)$ & $29.8(6.7)$ & $25.4(4.8)$ & $30.0(6.4)$ & $22.7(4.4)$ & $27.4(7.6)$ & $29.5(5.2)$ & $33.3(8.0)$ & $27.7(5.4)$ & 0.6032 \\
\hline Dyspnoea & $10.8(5.3)$ & $20.8(3.9)$ & $22.9(6.3)$ & $23.7(4.7)$ & $25.9(7.4)$ & $25.5(5.0)$ & $22.6(10.0)$ & $42.8(6.9)$ & $37.3(8.3)$ & $28.8(5.6)$ & 0.6989 \\
\hline Insomnia & $34.0(6.6)$ & $39.2(4.7)$ & $38.1(6.9)$ & $24.5(5.1)$ & $32.1(7.5)$ & $31.3(5.1)$ & $21.6(7.9)$ & $35.9(5.5)$ & $27.0(8.5)$ & $33.2(5.6)$ & 0.8300 \\
\hline Appetite loss & $18.6(6.5)$ & $24.0(4.8)$ & $17.2(7.0)$ & $17.2(5.1)$ & $17.2(6.6)$ & $17.7(4.5)$ & $8.8(5.7)$ & $17.0(4.0)$ & $15.7(7.1)$ & $18.6(4.6)$ & 0.6148 \\
\hline Constipation & $11.4(5.8)$ & $24.5(4.3)$ & $24.7(7.7)$ & $21.4(5.6)$ & $19.6(7.1)$ & $21.6(4.7)$ & $9.5(7.5)$ & $20.7(5.2)$ & $10.8(9.1)$ & $24.7(6.1)$ & 0.4017 \\
\hline Diarhoea & $9.6(3.8)$ & $4.7(2.8)$ & $15.3(5.5)$ & $6.5(4.1)$ & $8.6(4.7)$ & $9.3(3.0)$ & $13.4(6.1)$ & $8.9(4.2)$ & $9.5(4.1)$ & $4.6(2.7)$ & 0.3784 \\
\hline Financial Problems & $14.7(5.1)$ & $11.4(3.8)$ & $30.4(6.3)$ & $13.5(4.6)$ & $29.7(7.3)$ & $19.1(4.8)$ & $34.4(7.6)$ & $20.8(5.4)$ & $24.7(6.3)$ & $16.5(4.3)$ & 0.0842 \\
\hline Body image & $82.7(4.2)$ & $83.4(3.2)$ & 70.7 (6.3) & $77.1(4.8)$ & $78.0(5.0)$ & $84.9(3.5)$ & $82.0(5.9)$ & $77.6(4.3)$ & $77.4(6.6)$ & $72.9(4.5)$ & 0.8575 \\
\hline Sexual functioning & $22.2(5.0)$ & $12.3(3.7)$ & $23.1(5.0)$ & $13.8(4.0)$ & $30.8(6.7)$ & $15.1(4.7)$ & $32.6(6.4)$ & $13.8(4.8)$ & $28.7(6.9)$ & $14.5(4.8)$ & 0.0240 \\
\hline Future perspective & $39.9(6.3)$ & $30.4(4.9)$ & $32.3(7.2)$ & $41.4(5.3)$ & $46.1(8.0)$ & $48.8(5.4)$ & $44.2(8.8)$ & $40.0(6.4)$ & $49.7(10.2)$ & $54.9(6.6)$ & 0.6710 \\
\hline Systematic therapy & $16.1(3.2)$ & $18.7(2.5)$ & $33.8(4.9)$ & $27.9(3.6)$ & $20.2(3.7)$ & $19.2(2.6)$ & $20.9(4.6)$ & $26.6(3.2)$ & $25.6(4.3)$ & $21.6(2.8)$ & 0.7534 \\
\hline Breast symptoms & $20.9(4.1)$ & $20.0(3.1)$ & $20.3(3.8)$ & $11.5(2.7)$ & $15.9(3.2)$ & $9.8(2.2)$ & $14.0(4.6)$ & $10.2(3.3)$ & $14.6(4.8)$ & $6.8(3.1)$ & 0.0711 \\
\hline Arm symptoms & $13.7(3.5)$ & $17.5(2.7)$ & $22.9(5.3)$ & $20.5(3.8)$ & $23.3(4.9)$ & $17.4(3.4)$ & $23.1(6.1)$ & $24.7(4.3)$ & $15.9(5.8)$ & 17.9 (3.8) & 0.8310 \\
\hline Hair loss & $2.7(2.9)$ & $4.3(2.3)$ & $22.0(8.4)$ & $34.8(6.2)$ & $10.9(6.2)$ & $5.3(4.1)$ & $8.6(6.7)$ & $15.0(4.5)$ & $3.0(8.8)$ & $16.5(6.1)$ & 0.2799 \\
\hline
\end{tabular}

Legends: QoL Quality of life

${ }^{a}$ Estimates for themean scores estimated via the linearmixedmodeling expressed in absolute score points of the scale. Higher values for the symptomscales (Diarrhea, Loss of appetite, Nausea/vomiting, Fatigue) represent aworse level of symptoms. Higher values for the global health/Quality of Life scale represents a better level of functioning

${ }^{b} p$-value belongs to the comparison between age groups 


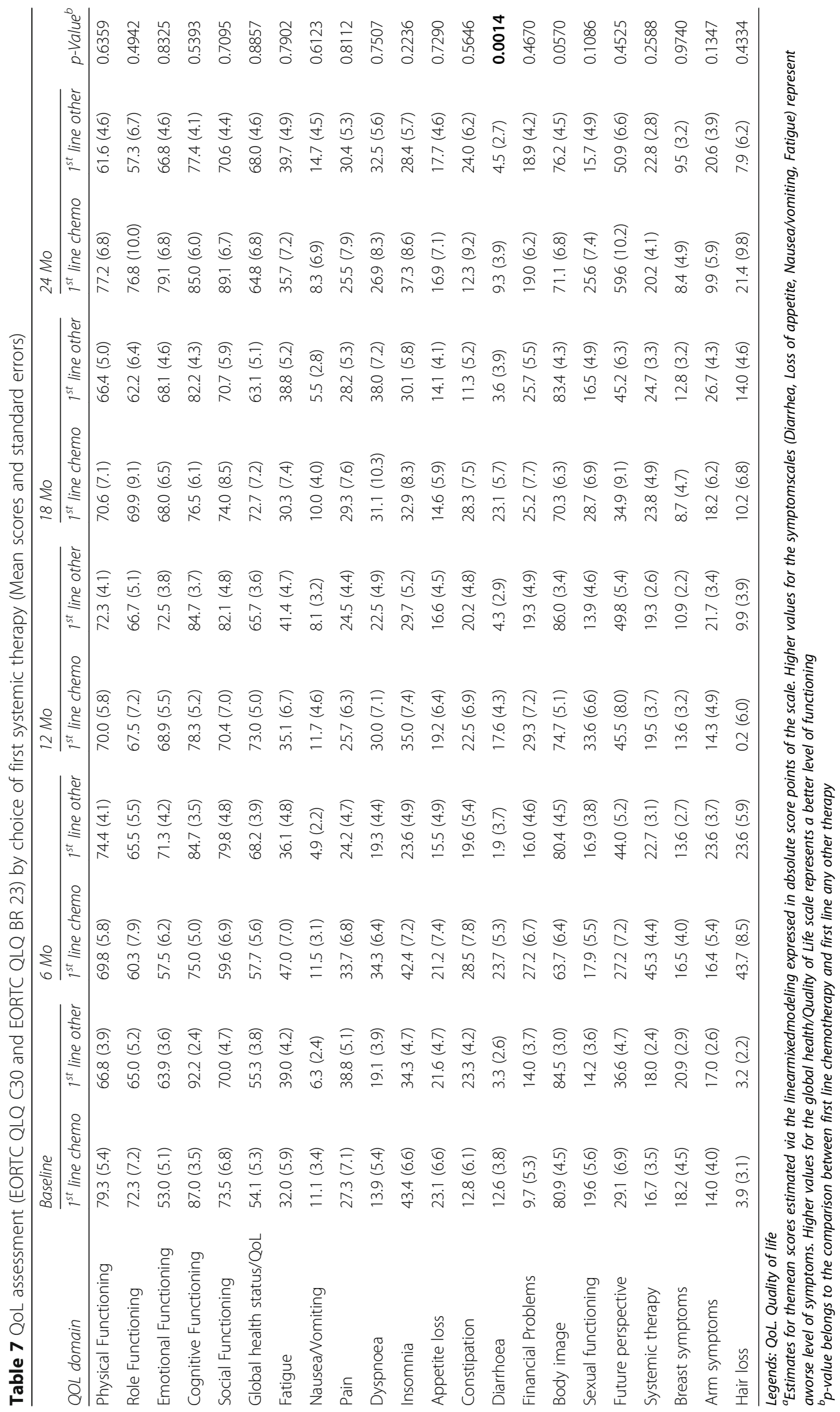




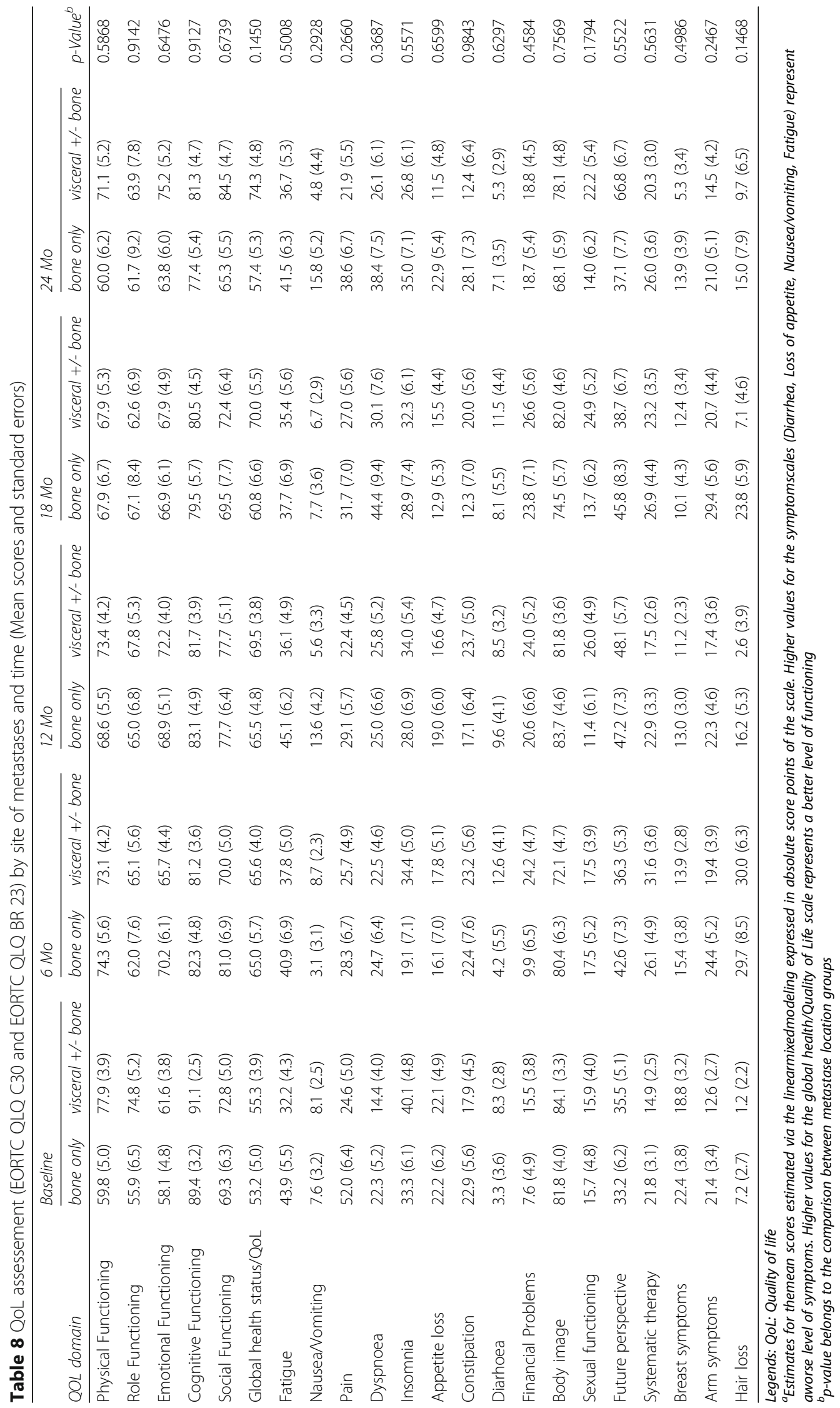


Interestingly, patients with only bone metastases reported worse physical and role functioning and pain compared to patients with visceral metastases. Pain is a leading symptom in patients with bone metastases, and an important factor influencing QoL [31].

Strengths of our study are the prospective randomized design, good compliance of the patients with QoL assessment, and relatively long follow-up. Apart from one study in abstract form [19], this is the first full publication to evaluate the impact of primary surgery on QoL in patients presenting with MBC.

\section{Study limitations}

A limitation of our study is that it stopped prematurely at 4 years because of slow recruitment. Our findings based on the relatively small number of patients in both arms need to be confirmed in following studies.

\section{Conclusion}

Our prospective randomized trial showed that primary surgery does not improve nor alter QoL of patients with de novo stage IV BC. Global health status and physical functioning were predictors for OS and could be use as additional marker for prediction of OS and TTTd in patients with de novo Stage IV BC.

\section{Abbreviations}

ABCSG: Austrian Breast and Colorectal Study Group; BC: Breast cancer; CTX: Chemotherapy; EORTC QLQ-BR23: European Organisation for Research and Treatment of Cancer Quality of Life Questionnaire - BR (Breast) 23; EORTC QLQ-C30 core questionnaire: European Organisation for Research and Treatment of Cancer Quality of Life Questionnaire - C30; HR: Hazard ratio; MBC: Metastatic breast cancer; OS: Overall survival; TTPd: Time to distant metastases; TTPI: Time to locoregional metastases; QoL: Quality of life

\section{Acknowledgements}

Not applicable

\section{Informed consent}

Informed consent (written) was obtained from all individual participants included in the study. All patients signed informed consent.

\section{Authors' contributions \\ $V B R, F F, G S, R G, M K, M G, M B$ were involved in the protocol writing, data collection, writing of the manuscript and the interpretation. PS,DE,RE, CS were involved in data collection and manuscript writing. VBR,FF, LS analysed and interpreted the patient data. All authors read and approved the final manuscript. \\ Funding \\ This study was sponsored by the Austrian Breast and Colorectal Cancer Study Group ( non-profit study group) . In addition, this study was supported by the Bürgermeister Fonds der Stadt Wien ("Medical Scientific Fund of the Mayor of the Federal Capital of Vienna"09057; Florian Fitzal) and Krebshilfe Steiermark (Cancer Aid Styria, Vesna Bjelic-Radisic). The both founder are a non-profit organisation with the aim to support scientific studies.}

\section{Availability of data and materials}

The datasets used and analysed during the current study are available from the corresponding author on reasonable request.
Ethics approval and consent to participate

The trial has been approved by local ethic authorities for each centres as following:

- Department of Gynecology and Obstetrics, Medical University Graz, Graz, Austria - ethic authority of Medical University Graz, Austria 10/06/2011

- Department of Surgery and Comprehensive Cancer Center, Medical University of Vienna, Vienna, Austria- ethic authority of Medical University Vienna, Vienna Austria 26/03/2009

- Department of Gynecology and Obstetrics, Medical University Innsbruck, Inssbruck, Austria- ethic authority of Medical University Innsbruck, Innsbruck, Austria 18/11/2011

- Department of Internal Medicine III with Hematology, Medical Oncology, Hemostaseology, Infectious Disease, Rheumatology, Oncologic Center, Laboratory for Immunological and Molecular cancer Research, Paracelsus Medical University Salzburg, Salzburg, Austriaethic authority of Medical University Paracelsus Salzburg, Salzburg, Austria 27/10/2011

- Department of Surgery, Ordens Hospital BHS Linz- ethic authority of Ordens Hospital BHS Linz, Linz, Austria 10/05/2011

- Breast Unit, Ordens Hospital "Elisabethinen" Linz- ethic authority of Ordens Hospital Elisabethinen Linz, Linz, Austria 04/10/2011

- Department of Gynecology and Obstetrics, Medical University Vienna, Vienna, Austria- - ethic authority of Medical University Vienna, Vienna Austria 13/04/2010

- Department of Internal Medicine Wels-Grieskirchen, Medical University Kepler University Hospital- ethic authority of Canton Oberösterreich Austria 18/03/2011 and 22/04/2011

- Department of Gynecology and Obstetrics and Surgery , Hospital Feldkirch- ethic authority of Canton Vorarlberg, Austria 28/03/2011

- Outpatient Department Dr Wette, St Veit, Austria- ethic authority of Canton Carinthia/ Austria 07/04/2011

- Department of Surgery, Hospital Güssing,Austria- ethic authority of Canton Burgerland, Austria 18/10/2011

\section{Consent for publication}

All authors and study participants have given their written consent for the publication.

\section{Competing interests}

Marija Balic is a member of the editorial board of BMC Cancer. All other authors have declared no conflicts of interest.

\section{Author details \\ ${ }^{1}$ Breast Unit, University Hospital Wuppertal, Heusnerstraße 40, 42283 Wuppertal, Germany. ${ }^{2}$ Department of Gynecology and Obstetrics, Medical University Graz, Graz, Austria. ${ }^{3}$ Department of Surgery and Comprehensive Cancer Center, Medical University of Vienna, Vienna, Austria. ${ }^{4}$ Breast Unit, Kantonsspital St. Gallen, St. Gallen, Switzerland. ${ }^{5}$ Department of Internal Medicine, Medical University of Vienna, Vienna, Austria. ${ }^{6}$ Department of Gynecology and Obstetrics, Medical University Innsbruck, Inssbruck, Austria. ${ }^{7}$ Department of Internal Medicine III with Hematology, Medical Oncology, Hemostaseology, Infectious Disease, Rheumatology, Oncologic Center, Laboratory for Immunological and Molecular cancer Reseasrch, Paracelsus Medical University Salzburg, Salzburg, Austria. ${ }^{8}$ Department of Surgery, Medical University Linz, Linz, Austria. ${ }^{9}$ Division of Oncology, Department of Internal Medicine and Comprehensive Cancer Center, Medical University Graz, Graz, Austria. ${ }^{10}$ Department of Gynecology and Obstetrics, Medical University Vienna, Vienna, Austria. ${ }^{11}$ Statistics Department, Austrian Breast and Colorectal Cancer Study Group (ABCSG), Vienna, Austria.}

Received: 11 August 2019 Accepted: 23 April 2020

Published online: 06 May 2020

References

1. Torre LA, Bray F, Siegel RL, et al. Global cancer statistics 2012. CA Cancer J Clin. 2015:65:87-108

2. Kobayashi K, Ito Y, Matsuura M, et al. Impact of immunohistological subtypes on the long-term prognosis of patients with metastatic breast cancer. Surg Today. 2016;46:821-6. 
3. Mariotto AB, Etzioni R, Hurlbert M, et al. Estimation of the Number of Women Living with Metastatic Breast Cancer in the United States. Cancer Epidemiol Biomarkers Prev. 2017;26(6):809-15. https://doi.org/10.1158/10559965.EPI-16-0889 Epub 2017 May 18.

4. Smith I. Goals of treatment for patients with metastatisc breast cancer. Semin Oncol. 2006;33(Suppl2):S2-5.

5. Cardoso F, Costa A, Senkus E, et al. 3rd ESO-ESMO International Consensus Guidelines for Advanced Breast Cancer [ABC 3]. Ann Oncol. 2017;28:16-33.

6. Petrelli F, Barni S. Surgery of primary tumors in stage IV breast cancer: an updated meta-analysis of published studies with meta-regression. Med Oncol. 2012:29:3982-290.

7. Badwe R. R. Hawaldar, N. Nair, et al. Locoregional treatment versus no treatment of the primary tumour in metastatic breast cancer: an open-label randomised controlled trial. Lancet Oncol. 2015;16:1380-8.

8. Sandri MT, Zorzino L, Cassatella MC, et al. Changes in circulating tumor cell detection in patients with localized breast cancer before and after surgery. Ann Surg Oncol. 2010;17:1539-45.

9. Fisher B, Gunduz N, Coyle J, et al. Presence of a growth-stimulating factor in serum following primary tumor removal in mice. Cancer Res. 1989:498: 1996-2001.

10. Cady B, Nathan NR, Michaelson JS, et al. Matched pair analyses of stage IV breast cancer with or without resection of primary breast site. Ann Surg Oncol. 2008;15:3384-95.

11. Dominici L, Najita J, Hughes $M$, et al. Surgery of the primary tumor does not improve survival in stage IV breast cancer. Breast Cancer Res Treat. 2001; 129(2):459-65.

12. Soran A, Ozmen V, Ozbas S, et al. A randomized controlled trial evaluating resection of the primary breast tumor in women presenting with de novo stage IV breast cancer: Turkish Study [Protocol MF07-01]. J Clin Oncol. 2016; 34(Suppl):1005.

13. Fitzal F, Bjelic-Radisic $V$, Knauer M, et al. Impact of breast surgery in primary metastasized breast cancer: Outcomes of the prospective randomized phase III ABCSG 28 POSYTIVE trial. Ann Surg. 2018. https://doi.org/10.1097/ SLA.0000000000002771.

14. Aaronson NK, Ahmedzai S, Bergman B, for the European Organization for Research and Treatment of Cancer Study Group on Quality of Life, et al. The European Organization for Research and Treatment of Cancer QLQ-C30: quality of life instrument for use in international clinical trials in oncology. $\mathrm{NCl}$. 1993;85:365-76.

15. Sprangers $M$, Groenvold M, Arraras Jl, et al. The European Organisation for Research and Treatment of Cancer: Breast Cancer Specific Quality of Life Questionnaire Module: First results from a three-country field study. J Clin Oncol. 1996;14:2756-68.

16. Fayers P, Aaronson N, Bjordal K, et al. EORTC QLQ-C30 Scoring Manual.3rd ed. Bruessels: EORTC Publication; 2001.

17. Osoba D, Rodrigues G, Miles J, et al. Interpreting the significance of changes in health-related quality of life score. J Clin Oncol. 1998;16:139-44.

18. Ghsialn I, Zikos E, Quinten C, et al. Health-related quality of life in locally advanced and metastatic breast cancer: methodological and clinical issues in randomised controlled trials. Lancet Oncol. 2016;17(7):e294-304. https:// doi.org/10.1016/S1470-2045(16)30099-7.

19. Soran A, Ozmen V, Ozbas S, et al. Early follow up of a randomized trial evaluation resect ion oft he primary breast tumor in women presenting with de novo stage IV breast cacner; Turkish Study. Protocol MF07-01. Cancer Res. 2014;73(24 Supplement):S2-03. https://doi.org/10.1158/00085472.SABCS13-S2-03.

20. Luoma M, Hakamies-Blomqvist L. The meaning of quality of life in patients being treated for advanced breast cancer: a qualitative study. PsychoOncology. 2004;13:729-7.

21. Scott NW, Fayers PM, Aaronson NK et al. EORTC QLQ-C30 Reference Values. 2008; EORTC QoL Study Group.

22. Rajendra A, Badwe RA, Parmar $V$, et al. Surgical removal of primary tumor in metastatic breast cancer: impact on health-related quality of life [HR-QoL] in randomized controlled trial [RCT]. Proc Am Soc Clin Oncol. 2014;32(8suppl 5S):abstr 1124

23. Warren M. Uncertainty, lack of control and emotional functioning in women with metastatic breast cancer: a review and secondary analysis of the literature using the critical appraisal technique. Eur J Cancer Care. 2010;19: 564-74.

24. Fulton C. Patients with metastatic breast cancer: their physical and psychological rehabilitation needs. Int J Rehabil Res. 1999;22:291-301.
25. Kershaw T, Northouse L, Kritprachia C, et al. Coping strategies and quality of life in women with advanced breast cancer and their family caregivers. Psychol Health. 2004;19:139-55.

26. Kenne-Sarenmalm E, Ohlen J, Jonsson $\mathrm{T}$, et al. Coping with recurrent breast cancer: predictors of distressing symptoms and health-related quality of life. J Pain Symptom Manag. 2007;34:24-39.

27. Harbeck N, lyer S, Turner M, et al. Quality of life with palbociclib plus fulvestrant in previously treated hormone receptor-positive, Her2 -negative metastatic breast cancer: patient-reported outcomes from PALOMA-3 trial. Ann Oncol. 2016;27:1047-54.

28. Holzner B, Kemmler G, Meraner $V$, et al. Fatigue in ovarian carcinoma patients: a neglected issue. Cancer. 2003;97:1564-72.

29. Hermelink K, Buehner M, Ph S, et al. Chemotherapy and Post-traumatic Stress in the Causation of Cognitive Dysfunction in Breast Cancer Patients. JNCI J Natl Cancer Inst. 2017;109(10):djx057.

30. Sato C, Sekiguchi A, Kawai M, et al. Postoperative Structural Brain Changes and Cognitive Dysfunction in Patients with Breast Cancer. PLOS ONE. 2015. https://doi.org/10.1371/journal.pone.0140655 November4.

31. Mavrogenis AF, Angelini A, Vottis C, et al. Modern Palliative Treatments for Metastatic Bone Disease: Awareness of Advantages, Disadvantages, and Guidance. Clin J Pain. 2016;32(4):337-50. https://doi.org/10.1097/AJP. 0000000000000255

\section{Publisher's Note}

Springer Nature remains neutral with regard to jurisdictional claims in published maps and institutional affiliations.
Ready to submit your research? Choose BMC and benefit from:

- fast, convenient online submission

- thorough peer review by experienced researchers in your field

- rapid publication on acceptance

- support for research data, including large and complex data types

- gold Open Access which fosters wider collaboration and increased citations

- maximum visibility for your research: over $100 \mathrm{M}$ website views per year

At BMC, research is always in progress.

Learn more biomedcentral.com/submissions 